\title{
FATORES DE INFLUÊNCIA NA CRIATIVIDADE EM EQUIPES DE PROJETO
}

\author{
Stefan von der Heyde Fernandes \\ Universidade Federal do Rio Grande do Sul - UFRGS \\ stefanufrgs@gmail.com \\ Priscila Zavadil Pereira \\ Universidade Federal do Rio Grande do Sul - UFRGS \\ prizav@yahoo.com.br \\ Júlio Carlos de Souza van der Linden \\ Universidade Federal do Rio Grande do Sul - UFRGS \\ julio.linden@ufrgs.br \\ Tânia Luisa Koltermann da Silva \\ Universidade Federal do Rio Grande do Sul - UFRGS \\ tania.silva@ufrgs.br \\ Régio Pierre da Silva \\ Universidade Federal do Rio Grande do Sul - UFRGS \\ regio.silva@ufrgs.br
}

\begin{abstract}
Resumo: Por muito tempo, o conceito de criatividade esteve associado às as teorias que buscavam compreender as características da personalidade dos indivíduos considerados criativos. As teorias mais recentes, contudo, passaram a discutir a importância do contexto na criatividade de indivíduos e grupos, incluindo o trabalho em equipe, o papel de lideranças, o ambiente social e o campo de conhecimento no qual as pessoas estão inseridas. Desse modo, o presente artigo busca identificar os fatores que influenciam a criatividade individual, assim como os fatores que afetam a criatividade em equipes de projeto, a fim de relacioná-los no campo do design. Para tanto, o trabalho utiliza a revisão de literatura sobre criatividade e design e sobre teorias que abordam a criatividade individual e em contexto. A partir deste enfoque teórico, o artigo apresenta um modelo que relaciona os fatores individuais e sociais que podem influenciar a criatividade de equipes de design.
\end{abstract}

Palavras-chave: design, criatividade, equipes de projeto.

Abstract: For a long time, the concept of creativity was associated with the theories that sought to understand the personality characteristics of 
individuals considered creative. The most recent theories, however, came to discuss the importance of creativity in the context of individuals and groups, including teamwork, the role of leaders, the social environment and the field of knowledge in which people are embedded. Thus, this article seeks to identify the factors that influence individual creativity, as well as factors that affect the creativity in project teams in order to relate them in the design field. To this end, the paper uses the literature review on creativity, design and theories that address individual creativity and context. From this theoretical approach, the paper presents a model that relates the individual and social factors that can influence the creativity of design teams.

Keywords: design, creativity, project teams.

\section{INTRODUÇÃO}

Embora a criatividade seja um assunto discutido através de teorias que vem desde Platão, pela filosofia, passando pela sociologia, epistemologia, psicologia e, mais recentemente, pela neurociência, seus conceitos por vezes não são claros e bem definidos. Contudo, há certo consenso que a criatividade está associada com a produção de algo novo e de ideias apropriadas a um determinado problema ou oportunidade (AMABILE, 1997; AMABILE, FISCHER, 2009; LUBART, 2007). Para muitos pesquisadores, a criatividade é uma qualidade de pessoas, um conjunto de traços de personalidade, características cognitivas e estilo pessoal. Além disso, a criatividade é também uma qualidade de ideias e produtos que é validada pelo julgamento social e explicações de criatividade podem englobar as características das pessoas, os fatores situacionais e a interação entre eles (AMABILE, 1995).

Essa visão contextual da criatividade vem sendo a mais explorada atualmente, ao lado de pesquisas dos campos das ciências cognitivas e da neurociência, que procuram compreender o funcionamento da mente humana. Grande parte dos trabalhos que relacionam a criatividade individual com a criatividade em equipes parte de estudos da psicologia ou da administração (PIROLA-MERLO, MANN, 2004; TAGGAR, 2002) e, no campo do Design, os estudos costumam analisar as habilidades de profissionais experientes ou estudantes e novatos no processo criativo e projetual, através de análises de protocolo, por exemplo (CROSS, 2007).

Desse modo, esse artigo procura investigar como o trabalho em equipe afeta a criatividade de designers, relacionando os fatores do indivíduo com os fatores contextuais, que incluem o trabalho em grupo, a organização e o ambiente no qual as pessoas estão inseridas. Essa pesquisa ocorre no âmbito teórico, através do estudo bibliográfico de pesquisas realizadas nesse campo, a fim de fornecer um embasamento para novos estudos que possam analisar as relações entre a criatividade individual e em equipe na prática projetual.

\section{TEORIAS E CONCEITOS DE CRIATIVIDADE}

Por muito tempo a criatividade foi vista como algo divino. Acreditava-se que os músicos, poetas e artistas não produziam suas obras através de seu próprio esforço, mas que eram inspirados por um poder super-humano. Até o século XIX a criatividade era vista como algo que surgia de modo inconsciente (NOVAES, 1971). 
Seguindo as teorias evolucionistas de Darwin, surgiu a teoria da criatividade como força vital. A criatividade foi então considerada como uma força inerente à vida e, desta forma, qualquer matéria orgânica seria fundamentalmente criadora (KNELLER, 1978). Essa teoria converge ao pensamento vital de Ostrower (2010), a qual afirma que criar é formar, sendo, portanto, um potencial inerente ao homem e algo indispensável às suas necessidades existenciais.

Para alguns autores a criatividade não é apenas o resultado de uma necessidade inerente ao homem, mas é, também, um processo. Mesmo a célebre frase de Arquimedes "Eureca", não surgiu de forma aleatória em seu instante de iluminação sem que houvesse uma substancial preparação. O momento de sua descoberta, portanto, não parece ser um resultado de inspiração divina, vital ou cósmica, mas a conclusão da busca extensiva em solucionar um determinado problema (BAXTER, 2000).

No final da década de 1950 surgiu um movimento interdisciplinar interessado no estudo da cognição humana: a Ciência Cognitiva, composta por disciplinas como a psicologia, a linguística, a neurociência, a ciência da computação, a antropologia e a filosofia (NEUFELD, BRUST, STEIN, 2011). Este campo contribuiu para os estudos que buscam os processos mentais, assim como "possibilitou a transferência de tecnologias intelectuais para as tecnologias computacionais" (MEDEIROS, 2004, p.3).

No início da década de 1960 a neurociência também começou a analisar a criatividade. Um dos pioneiros pesquisadores nesta área foi Roger W. Sperry, psicobiólogo que identificou os métodos contrastantes utilizados pelos hemisférios direito e esquerdo do cérebro humano. O hemisfério esquerdo se especializa no pensamento verbal, lógico e analítico, enquanto o hemisfério direito funciona de maneira não verbal, especializando-se em informações visuais, espaciais, perceptivas, ou seja, seu estilo de processamento é não linear (EDWARDS, 2002). Ned Herrmann criou a teoria do cérebro total, que identifica que a criatividade manifesta-se em diferentes áreas do cérebro (KOWALTOWSKI et al., 2011).

Assim, foi então a partir dos anos 1950, que os estudos sobre a criatividade obtiveram um caráter científico, dissociando-se dos conceitos de divindade e genialidade.

\section{TEORIAS SOBRE A CRIATIVIDADE DO INDIVÍDUO}

Os estudos sobre a criatividade em indivíduos muitas vezes se inter-relacionam com pesquisas sobre a inteligência humana. Já em finais do século XIX e no início do século XX a psicologia buscava investigar e mensurar as diferenças individuais dos seres humanos, quando, em torno de 1900, o psicólogo francês Alfred Binet propôs o chamado teste de inteligência, cujo resultado é conhecido como QI. Para Binet, as faculdades mentais de cada sujeito são únicas e independentes e seus testes são apropriados para analisar as faculdades singulares. Outras avaliações surgiram ao longo do tempo seguindo essa visão unidimensional sobre o funcionamento da mente das pessoas (GARDNER, 1995; GUILFORD, 1967).

Embora muito disseminados, esses testes e a visão unitária de inteligência geraram contradições. Posteriormente, com as ciências cognitivas e a neurociência, surgiram teorias que trazem uma visão pluralista da mente, reconhecendo que os indivíduos possuem forças cognitivas diferenciadas e estilos cognitivos contrastantes. 
Essa abordagem deu origem à Teoria das Inteligências Múltiplas, do psicólogo Howard Gardner (GARDNER, 1995).

Gardner define a inteligência como a capacidade de resolver problemas ou de elaborar produtos que sejam valorizados em ambientes culturais ou comunitários. Para o psicólogo, há várias inteligências autônomas que funcionam de modo combinado. Essas inteligências são agrupadas em sete tipos, sendo elas: linguística; lógico-matemática; espacial; musical; corporal-cinestésica; interpessoal; e intrapessoal (GARDNER, 1995).

A partir desses estudos, novas teorias surgiram tendo como ponto de convergência a definição de que inteligência e criatividade não são capacidades globais, mas situam-se em contextos específicos. Para Gardner (2000), o que difere a inteligência da criatividade é que esta surge apenas em algumas áreas e abrange o indivíduo criador, o domínio de realização de sua produção e o conjunto de indivíduos que julgam a qualidade da criação (KOWALTOWSKI et al., 2011).

Para Guilford (1967) a inteligência não reflete diretamente a criatividade de um indivíduo, mas o indivíduo criativo é capaz de pensar, como o autor denomina, de forma divergente. $O$ pensamento divergente rompe com os padrões mentais para buscar novas conexões e encontrar soluções inusitadas, movendo-se em várias direções à procura de uma resposta e, assim, produz uma gama de soluções adequadas ao problema (KOWALTOWSKI et al., 2011).

Assim, a maior parte dos estudos sobre o assunto concluiu que a inteligência está mais relacionada à organização de informações, realização de escolhas originais, concentração de atenção e à realização correta de tarefas, o que favorece o ato criador, mas não são condições suficientes para a criatividade (KOWALTOWSKI et al., 2011). Desse modo, inteligência e criatividade, embora relacionadas, são capacidades distintas (FEIST, BARRON, 2003; GUILFORD, 1950; SNYDERMAN, ROTHMAN, 1987; STERNBERG, 2006).

Para Kneller (1978) a pessoa criativa possui como qualidades: a consciência; a fluência; a flexibilidade; a originalidade; a elaboração; o ceticismo; a persistência; o humor; o inconformismo; e a autoconfiança. Da mesma forma, para Guilford (1967) as características do indivíduo criativo incluem a fluência, a flexibilidade, a originalidade, a elaboração, além da sensibilidade para perceber problemas e a redefinição, no sentido de perceber questões já conhecidas sob um novo ponto de vista.

Esses aspectos do pensamento das pessoas criativas foram aceitos e adotados na grande maioria dos estudos relativos ao tema. Em pesquisas como a de Feist e Barron (2003) é apontada também uma possível relação entre o comportamento criativo e a autoconfiança, abertura, tolerância e afetividade como fatores de influência da personalidade dos indivíduos (FEIST, BARRON, 2003).

Contudo, além dos traços de personalidade, as contribuições para o estudo da criatividade que surgiram a partir dos anos 1980 voltaram-se para a influência dos fatores sociais e culturais no desenvolvimento da criatividade. Desse modo, além das características do sujeito criador há a influência do ambiente no qual o indivíduo se encontra, substituindo a abordagem individualista por uma visão sistêmica da criatividade (ALENCAR \& FLEITH, 2003).

\section{CRIATIVIDADE NO CONTEXTO}


Dentre as teorias recentes sobre a criatividade os estudos de Teresa Amabile (1995; 1997; 2009) são uma das referências mais significativas. Sua contribuição está no apontamento da importância da motivação intrínseca das pessoas para atingir um objetivo. Nesse sentido, as pessoas são mais criativas quando intrinsecamente motivadas e, embora essa motivação dependa da personalidade do indivíduo, o ambiente social também desempenha um papel significativo (AMABILE, 1997).

A Teoria Componencial da Criatividade Organizacional e Inovação, proposta por Amabile (1997), trata de como os elementos do ambiente de trabalho impactam a criatividade dos indivíduos. Assim, o ambiente social, de trabalho, influencia a criatividade por ter efeito sobre os componentes individuais e o impacto do ambiente sobre a motivação é o mais imediato e direto.

Segundo essa teoria (Figura 1), a criatividade do indivíduo, mesmo em uma equipe, é resultado da expertise (o conjunto de caminhos cognitivos que podem ser seguidos para resolver um problema e inclui a memória para o conhecimento, a proficiência técnica e os talentos específicos ao domínio do trabalho), das habilidades criativas (que dependem de características do indivíduo como independência, autodisciplina, tolerância, perseverança e flexibilidade cognitiva) e da motivação intrínseca. Por sua vez, a criatividade do indivíduo ou equipe é influenciada pelo ambiente de trabalho, que envolve: (i) a motivação organizacional, compreendendo a abertura, a comunicação ativa de informações e ideias, o reconhecimento e a avaliação do trabalho da equipe, assim como a abstenção de críticas destrutivas, de controle absoluto pelo gestor e do excesso de procedimentos formais; (ii) a disponibilidade de recursos, como tempo, pessoas, materiais, informações, treinamento e recursos financeiros; e (iii) as práticas de gestão, como o apoio aos grupos de trabalho, o lançamento de projetos desafiadores, a supervisão do projeto e liderança, incluindo a definição de objetivos claros, o planejamento e feedbacks, a comunicação entre as pessoas e a capacidade de formação de grupos de trabalho que possuam habilidades distintas e que sejam capazes de desafiar suas ideias de modo construtivo (AMABILE, 1997).

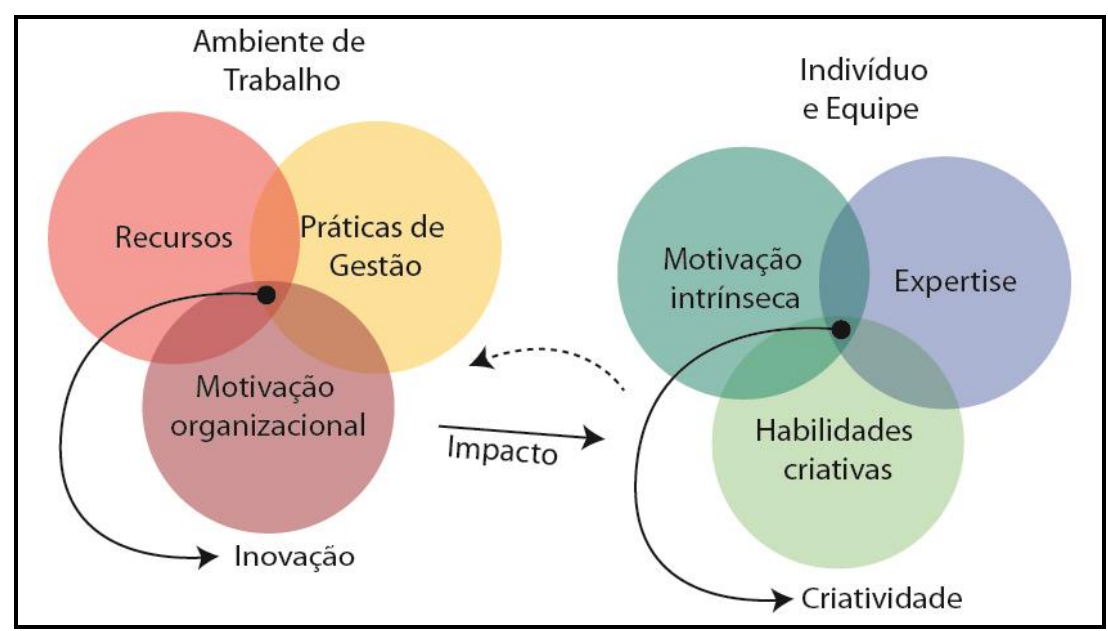

Figura 1: The Componential Theory of Organizational Creativity and Innovation. Fonte: adaptado de Amábile, 1997.

Em convergência com esse modelo encontra-se também a Teoria do Investimento em Criatividade, de Sternberg (1988, apud ALENCAR, FLEITH, 2003), que inclui os aspectos do modelo componencial, como a motivação e o contexto 
ambiental, assim como aspectos da personalidade dos indivíduos, tais como a predisposição a correr riscos, a autoconfiança, a tolerância, coragem para expressar novas ideias, perseverança e autoestima. Além disso, compreende a inteligência enquanto a capacidade de redefinir problemas, de analisar e reconhecer as melhores ideias e de persuadir as outras pessoas sobre o valor de suas próprias ideias, bem como os estilos intelectuais e o conhecimento relativo a uma determinada área.

Seguindo essa mesma abordagem, há a Perspectiva de Sistemas, de Csikszentmihalyi (1988), defendendo que o foco dos estudos em criatividade deve estar nos sistemas sociais, e não apenas no indivíduo. De acordo com essa teoria, a criatividade não ocorre dentro do indivíduo, mas é resultado da interação entre o contexto sociocultural e o pensamento de um sujeito. Assim, a criatividade deve ser compreendida como um processo sistêmico, que depende das características da personalidade e das experiências pessoais do indivíduo, do campo, ou sistema social, no qual se está inserido, incluindo todos os indivíduos que julgam se uma nova ideia ou produto é criativo, e o domínio, ou seja, a área que compreende o conhecimento acumulado, estruturado, transmitido e compartilhado em uma sociedade (CSIKSZENTMIHALYI, 1988).

Essas teorias passaram a ser mais exploradas no contexto organizacional, a fim de aprimorar práticas de gestão e impulsionar a criatividade e a inovação nas empresas. Agars et al (2012) traz um estudo que busca demarcar o papel do contexto das organizações no desenvolvimento da criatividade individual, discutindo também o impacto da liderança nesse cenário. Nesse sentido, um dos primeiros modelos multiníveis de criatividade foi proposto por Woodman, Sawyer e Griffin (1993), na Teoria da Criatividade Organizacional, segundo a qual fatores organizacionais como a cultura, os recursos, sistemas de recompensa, a estratégia da empresa, a estrutura e a tecnologia disponível influenciam o comportamento criativo individual.

Dentre as principais teorias sobre a criatividade organizacional está também a Teoria da Ação Criativa em Domínios Sociais Múltiplos (Ford, 1996), a qual considera que os domínios, ou seja, as áreas de conhecimento, representam contextos independentes, nos quais as regras para o comportamento criativo podem ser desenvolvidas e muitos dos estudos de criatividade são realizados em domínios que podem não ser generalizados para uma determinada organização (AGARS et al, 2012).

No campo do design, Christiaans (1992) defende esta ideia segundo a qual o tipo e o conteúdo do conhecimento utilizado depende do domínio no qual o problema pertence, além da estrutura do problema e da expertise do solucionador do problema. O desenvolvimento dessa expertise está inicialmente relacionado à aprendizagem do conhecimento processual: a aprendizagem sobre como solucionar um problema. No caso específico do design, a principal diferença para as outras áreas reside no fato de as áreas projetuais lidarem com problemas mal estruturados (CROSS, 2007). O conhecimento específico da área de design favorece a criatividade, pois utiliza tanto o conhecimento técnico, semântico e metodológico dos processos, quanto técnicas criativas, imaginação e modelos não lineares de pensamento, unindo a lógica e a imaginação (TSCHIMMEL, 2010).

\section{DESIGN E CRIATIVIDADE}

Da mesma forma que o design busca produzir produtos inovadores para as necessidades dos usuários, segundo Lubart (2007), a criatividade é a capacidade de 
realizar uma produção que seja, ao mesmo tempo, nova e adaptada ao contexto na qual ela se manifesta. Esta produção nova é original e imprevista, se diferenciando de qualquer outra solução já anteriormente criada por outras pessoas (LUBART, 2007). Ao mesmo tempo, a produção criativa não pode ser simplesmente nova, mas, também, útil no seu contexto (BODEN, 1999; LUBART, 2007). Isto significa que a ideia original deve ser igualmente adaptada, para que atenda as necessidades das pessoas.

Löbach (2001) reforça que a configuração de um produto não se dá em um ambiente vazio, cada objeto de design é o resultado de um processo de desenvolvimento centrado nas necessidades dos usuários. Isto exige do profissional a habilidade de associar o seus conhecimentos e experiências com o problema de projeto, tornando a sua solução útil, original e inovadora para o contexto em que se insere (LÖBACH, 2001).

Para Alencar (1996), o desafio de aliar alta qualidade e baixo custo frente às exigências cada vez maiores dos usuários, tem sido um dos fatores contribuintes para despertar a consciência das organizações para o potencial criativo de seus recursos humanos. Esta competitividade também exige a capacidade de projetar produtos inovadores em espaços de tempo cada vez mais curtos. Por isso, métodos para aperfeiçoar o processo de projetos de produto foram desenvolvidos nas últimas décadas, através diferentes abordagens para as etapas de metodologia de projeto.

No entanto, apenas o uso de metodologia de desenvolvimento de projetos não assegura que o resultado culminará em um produto inovador para o mercado, ou que este seja o resultado da criatividade de seus desenvolvedores. Pelo contrário, observase que muitas empresas evitam investir capital financeiro em recursos humanos com foco em criatividade devido ao risco de fracasso e a insegurança de não poder mensurar significativamente os recursos na cadeia produtiva (BAXTER, 2000). Além disso, as empresas não encontram em seus funcionários as características necessárias que resultem em produtos inovadores (ALENCAR, 1996).

A forma distinta de pensar do designer, popularmente conhecida como "Design Thinking", pode contribuir significativamente para a inovação das empresas atuais devido às suas características (ALMENDRA e CHRISTIAANS, 2013). O design thinking se refere ao raciocínio projetual, a uma forma diferente de pensamento, atrelada ao pensamento abdutivo. A abdução, diferente do raciocínio dedutivo e indutivo, é o processo de formar hipóteses explicativas. A dedução prova algo que deve ser e a indução mostra algo que é atualmente operatório, partindo de uma premissa menor para uma maior. Já a abdução faz uma sugestão de algo que pode ser. Assim, o raciocínio abdutivo refere-se a hipóteses que são formuladas antes de uma confirmação ou negação de determinado caso (CROSS, 2007).

O termo design thinking vem sendo utilizado também em pesquisas acadêmicas e publicações na área na tentativa de compreender e explicar a maneira de pensar e solucionar problemas através do raciocínio projetual. De forma semelhante, Cross (2007), propõe que há formas projetuais de conhecimento, assim como existem as formas científicas e humanísticas. Entre os aspectos desse modo de conhecimento projetual, Cross (2007) identificou cinco características principais: os problemas com os quais os designers lidam são mal definidos; o modo de resolver os problemas é focado na solução; a forma de pensar é construtiva; são utilizados códigos que transformam requisitos em objetos concretos; e esses códigos são utilizados para "ler e escrever" 
em linguagens de objetos. Assim, a natureza do design thinking é exploratória e reflexiva (CROSS, 2007).

Além disso, o raciocínio projetual está associado à capacidade do pensamento lateral, termo introduzido por De Bono (1970) para designar o pensamento que se mostra contrário aos procedimentos de processos lógicos, chamados por ele de pensamento vertical. O pensamento lateral se refere ao movimento através dos padrões formados na mente, através de experiências pessoais, ao invés de seguir um caminho ao longo de determinado padrão, como ocorre no pensamento vertical. É preciso romper com as sequências de informações pré-estabelecidas para modifica-las e agrupá-las de forma diferente.

Outra característica dos designers é a habilidade de utilizar recursos visuais como forma de reflexão, expressão e comunicação de pensamento. Esta converge com a forma de pensamento não linear do pensamento visual apresentado por Arnheim (1986). O autor se refere ao modo de pensamento através da percepção, pois a interpretação do indivíduo do mundo é construída da mesma forma. O indivíduo criativo é, portanto, aquele que percebe o contexto em sua volta, e produz soluções baseado em suas reflexões e experiências anteriores.

Para Goldschmidt (1994) pensamento visual, percepção e visão são diferentes conceitos. A percepção significa a interpretação do que é apreendido pelos sentidos, incluindo a visão, que, por sua vez, é a função do equipamento óptico que informa configuação, cor, movimento e distância dos objetos no campo visual de um indivíduo. O pensamento visual refere-se à integração de mecanismos físicos da visão, da percepção e da atividade motora da representação. É o pensamento que dá origem a ideias por meio de imagens visuais e auxilia a criação de formas (GOLDSCHIMIDT, 1994; MEDEIROS, 2004).

O design tem como sua expertise o uso de imagens. O pensamento não verbal e a comunicação visual incluem uma vasta gama de elementos, "da graficacia às linguagens dos objetos, linguagens de ação e mapeamento cognitivo" (CROSS, 2007, p.29). A linguagem gráfica, assim, é uma das manifestações dos pensamentos, auxiliando também na comunicação de ideias e instruções para outros indivíduos (MEDEIROS, 2004).

Devido às exigências do mercado, os designers também devem possuir em seu repertório técnicas criativas para aperfeiçoar o processo de desenvolvimento de projeto. Segundo Baxter (2000) as técnicas específicas de criatividade podem estimular e impulcionar a capacidade de criação de qualquer indivíduo. Técnicas como Brainstorming (OSBORN, 1975) e suas variações, como Brainwriting, o método 635 e o Brainstorming eletrônico; método Delphi; Analogias Direta, Simbólica e Pessoal; método Sinético; e método da Instigação de Questões (MESCRAI), são exemplos de ferramentas que o designer aplica para otimizar a velocidade e qualidade para alcançar soluções e tomadas de decisões (BACK, et al., 2008; BAXTER, 2000).

O designer, portanto, deve possuir conhecimentos técnicos e teóricos para obtenção de bons resultados no emprego de diversas técnicas criativas, já que sua forma de trabalho utiliza formas de pensamento não linear e representações gráficas para solucionar os problemas existentes, em sua maioria, complexos e não estruturados. O designer é capaz de aplicar conscientemente o processo criativo ao desenvolvimento do projeto, ao mesmo tempo possibilita a avaliação objetiva dos resultados. 


\section{DISCUSSÃO}

A partir do referencial teórico abordado, identificou-se que o modelo proposto por Amábile (1997) reune as principais características relacionadas à criatividade do indivíduo e do contexto social, que também vão ao encontro das teorias de demais autores pesquisados. Assim, a fim de relacionar as características do profissional de design com as teorias sobre criatividade, este artigo propõe uma adaptação do modelo da Teoria Componencial da Criatividade Organizacional e Inovação (AMABILE, 1997), inserindo os aspectos específicos do design.

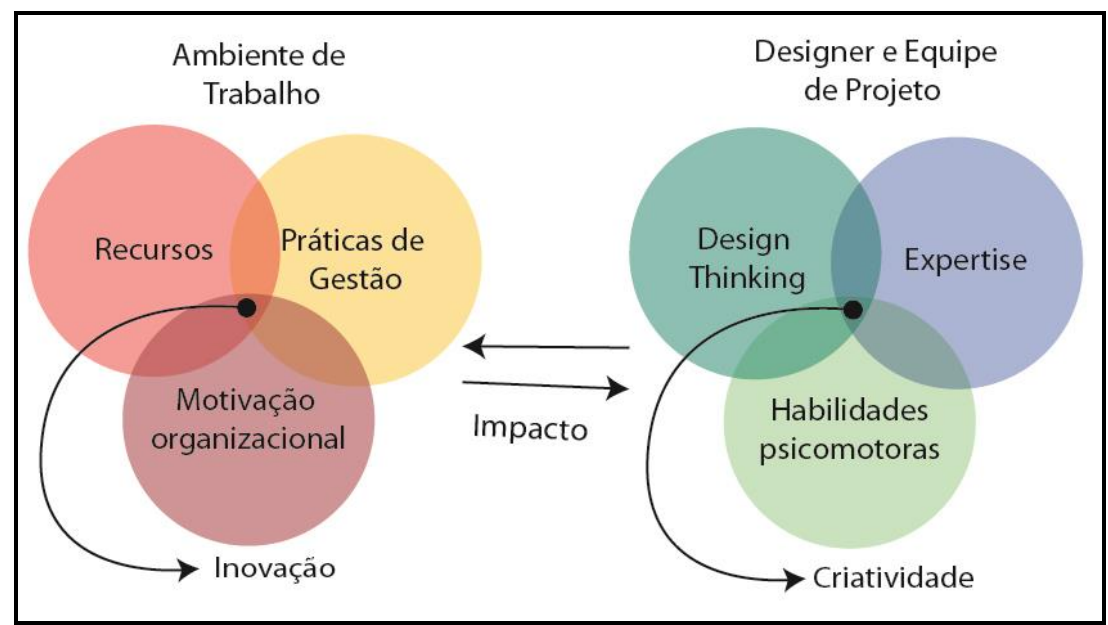

Figura 2: Teoria Componencial da Criatividade Organizacional e Inovação em Equipes de Projeto.

Elaborado pelos autores.

A respeito dos fatores relacionados ao indivíduo e à equipe, a adaptação do modelo original considera como habilidades criativas fundamentais para o designer e para a equipe de projeto a capacidade do pensamento visual (ARNHEIM, 1986), que auxilia na definição e estruturação do problema durante o processo criativo. 0 pensamento visual contribui para a expansão do espaço do problema-solução, por meio da conjugação de operações mentais com habilidades manuais (MEDEIROS, 2004). Assim, a expressão gráfica também é uma habilidade importante para a manifestação de ideias e soluções, bem como para a comunicação das mesmas entre os membros da equipe de projeto. Desse modo, o pensamento visual e a expressão gráfica se configuram como habilidades psicomotoras essenciais para o processo criativo do designer, permitindo a geração de ideias através de sketches, modelos e protótipos através da exploração de possibilidades, em um fluxo contínuo entre o pensamento analítico e sintético.

As habilidades psicomotoras estão diretamente relacionadas com a expertise do designer, que permitirá a co-evolução do problema e solução projetual durante o processo criativo (DORST, CROSS, 2011). Nesse contexto, as competências necessárias ao profissional e à equipe incluem o domínio de técnicas criativas e o conhecimento de metodologias projetuais. De acordo com Chirsthiaans (1992), o conhecimento processual de design, que inclui os saberes relacionados ao processo resolução de problemas, e os conhecimentos específicos da disciplina estão diretamente relacionados com a capacidade criativa do designer. Embora a metodologia não seja suficiente para garantir que se alcance uma solução nova e adequada ao problema, ela contribui para a organização e estruturação do processo de projeto e auxilia na 
aplicação do repertório do designer durante as etapas de desenvolvimento. Cabe considerar que existem diferentes linhas metodológicas no design e que essas diferenças na formação da cultura projetual do indivíduo também interferem em sua expertise e no processo criativo. Além disso, apesar de existirem críticas quanto à limitação da metodologia no processo criativo, os procedimentos metódicos não significam a mecanização do trabalho de design, mas permitem que o designer avalie e escolha os instrumentos que podem lhe ser úteis dependendo do contexto, das condições do projeto, das necessidades do cliente e da composição da equipe (TSCHIMMEL, 2010).

Além das habilidades psicomotoras e da expertise do design, incluindo conhecimentos específicos e metodológicos - processuais -, o design thinking também está relacionado à capacidade criativa do designer e da equipe projetual, contribuindo para a motivação intrínseca durante o processo. Pesquisadores da área defendem que existe uma forma de pensar típica do design, que se distingue de outras formas de pensamento, como o científico (CROSS, 2001, 2007; DORST, 2003). De acordo com Cross (2001), em comparação com o pensamento científico, o pensamento no design se centra desde o início em possíveis soluções e redefine o escopo do problema com base nas primeiras abordagens de resolução, caracterizando um procedimento coevolutivo no processo, no qual o problema inicial é redefinido diversas vezes em direção a possíveis soluções.

Desse modo, o pensamento do design se caracteriza como um tipo de pensamento abdutivo, que busca formar hipóteses explicativas, sugerindo algo que pode ser, diferente do pensamento indutivo e dedutivo. Assim, o raciocínio projetual se configura como exploratório e reflexivo (CROSS, 2007), o que pode contribuir para a motivação do indivíduo durante o processo criativo, na medida em que a imersão em uma única hipótese pode desmotivar o sujeito criador quando essa não alcançar o resultado desejado. O pensamento abdutivo permite navegar pelo espaço do problema e investigar diversas possibilidades de solução, motivando o indivíduo a visualizar diversos caminhos possíveis para alcançar determinado resultado.

Contudo, a motivação intrínseca também depende, conforme explica Amábile (1997), do interesse, envolvimento, curiosidade e do senso de desafio, além de ser influenciada pelo ambiente social, abrangendo a motivação organizacional, os recursos disponíveis e as práticas de gestão da organização.

\section{CONSIDERAÇÕES FINAIS}

Embora há muitas décadas existam estudos sobre a criatividade, evidenciando um grande número de pesquisas a respeito do assunto, existem poucas definições consensuais sobre o termo, sobre como ela se manifesta e sobretudo como pode ser mensurada.

Diante deste contexto, novas pesquisas sobre o tema se revelam um desafio, no sentido de revisar a vasta bibliografia existente e de definir conceitos com clareza. Contudo, as teorias mais recentes sobre o assunto, com origem na psicologia e, em alguns casos na administração, se assemelham e convergem para a necessidade de considerar as habilidades do indivíduo e o contexto - ambiente de trabalho, cultura, campo do conhecimento - como influenciadores mútuos da criatividade. Entretanto, na área do design, ainda há poucos trabalhos que consideram o contexto social e 
grande parte dos estudos busca analisar o processo criativo dos designers e suas habilidades individuais.

Assim, esse artigo procurou relacionar os fatores individuais do designer com o ambiente social trazendo as características específicas do campo do design, a partir do Modelo Componencial de Criatividade Organizacional e Inovação, segundo a revisão de literatura sobre o assunto.

Dessa forma, este é um estudo inicial de natureza teórica cujo objetivo é contribuir como referencial para novas pesquisas e, sobretudo, que possa auxiliar como fundamentação para trabalhos que analisem as influências do indivíduo e do contexto na criatividade em design a partir de pesquisa aplicada, verificando os resultados na prática projetual.

\section{REFERÊNCIAS}

AGARS, M. D.; KAUFMAN, J. C.; DEANE, A.; SMITH, B. Fostering individual creativity through organizational context: a review of recenet research and recommendations for organizational leaders. In: MUMFORD, M. D. (org) The handbook of organizational creativity. Elsevier, 2012.

ALENCAR, Eunice Soriano de., FLEITH, Denise de Souza. Contribuições teóricas recentes ao estudo da criatividade. Psicol. Teori. Pesqui, v. 19, n. 1, p. 1-8, 2003.

ALMENDRA, Rita; CHRISTIAANS, Henri. 'Design Thinking': The Emperor's New Suit. Design Principles and Practices: An International Journal, vol. 6, 2013.

AMABILE, T. M. Attributions of creativity: what are the consequences? Creativity Research Journal, 8, 1995, pp.423-426.

AMABILE, T, M. Motivating Creativity in Organizations. California Management Review, vol.40 n1, 1997, pp.39-58.

AMABILE, T. M.; FISHER, C. M. Stimulate creativity by fueling passion. In: E. Locke (Ed). Handbook of Principles of Organizational Behavior, 2 ed. John Wiley \& Sons: West Sussex, UK, 2009, pp.481-497.

ARNHEIM, R. El pensamiento visual. Barcelona: Paidos, 1986.

BACK, N.; OGLIARI, A.; DIAS, A.; SILVA, J. C. Projeto integrado de produtos: planejamento, concepção e modelagem. Barueri, SP: Manole, 2008.

BAXTER, Mike. Projeto de produto: guia prático para o design de novos produtos. $2^{\circ}$ ed. São Paulo: Edgard Blücher, 2000.

BODEN, Margareth A. Dimensões da Criatividade. Porto Alegre: Artes Médicas Sul, 1999.

CHRISTIAANS, H. C. M. Creativity in design: the role of domain knowledge in designing. Utrecht: Lemma, 1992.

CROSS, N. Design Cognition: results from protocol and other empirical studies of design activity. In: EASTMAN, MCCRACKEN, NEWSTETTER (Org). Design Knowing and Learning: cognition in design education. Elsevier Science, Oxford, 2001, pp. 79-103.

CROSS, Nigel. Designerly ways of knowing. London: Springer, 2007. 
CSIKSZENTMIHALYI, Mihaly. Society, culture, and person: A systems view of creativity. Cambridge University Press, 1988.

DORST, K. The problem of design problems. In: CROSS, N.; EDMONDS, E. Expertise in Design - Design Thinking Research Symposium 6. Creativity and Cognition Studios Press, Sidney, 2003. Disponível em: http://research.it.uts.edu.au/creative/design/ papers/23DorstDTRS6.pdf. Acesso em: 06.03.2014

DORST, K.; CROSS, N. Creativity in Design Process: co-evolution of problem-solution. In: Design Studies, vol.22, n5, setembro de 2001. Elsevier Science, pp.425-437.

EDWARDS, Betty. Desenhando com o artista interior. São Paulo: Claridade, 2002.

FEIST, G. J.; BARRON, F. X. Predicting creativity from early to late adulthood: intellect, potential and personality. Journal of Research in Personality, v 37, n1, 2003: pp. 62-88.

FORD, C. M. A theory of individual creativity in multiple social domains. Academy of Management Review, 21, 1996, 1112-1134.

GARDNER, H. Inteligências múltiplas: a teoria na prática. Porto Alegre: Artmed, 1995.

GARDNER, H. Inteligência: um conceito reformulado. Rio de Janeiro: Objetiva, 2000.

GOLDSCHIMIDT, G. On visual design thinking: the kids of architecture. Design Studies, v.15, n.2, p.158-174, 1994.

GUILFORD, J. P. Creativity. American Psychologist, 1950, v5, 444-454.

GUILFORD, J. P. The Nature of Human Intelligence. New York: McGraw-Hill, 1967.

KNELLER, G. F. Arte e Ciência da Criatividade. $5^{\circ}$ ed. São Paulo: IBRASA, 1978.

KOWALTOWSKI, D. C. C. K.; BIANCHI, G.; PETRECHE, J. R. D. A criatividade no processo de projeto. IN: PETRECHE, J. R. D.; FABRÍCIO, M. M. (Org). O Processo de Projeto em Arquitetura. São Paulo: Oficina de Textos, 2011.

LÖBACH, Bernd. Design industrial: bases para a configuração dos produtos industriais. São Paulo: Edgard Blucher, 2001.

LUBART, Todd. Psicologia da Criatividade. Porto Alegre: Grupo A. 2007.

MEDEIROS, L. Desenhística: a ciência e a arte de projetar desenhando. Santa Maria: sCHDs Editora, 2004.

NEUFELD, C. B,; BRUST, P. G.; STEIN, L. M. Bases epistemológicas da psicologia cognitiva experimental. Psicologia: Teoria e Pesquisa, vol. 27, n.1, 2011, pp.103-112.

NOVAES, Maria Helena. Psicologia da Criatividade. Petrópolis: Vozes Ltda. 1971.

OSBORN, A. F. O poder criador da mente. 4ed. São Paulo: IBRASA, 1975.

OSTROWER, Fayga. Criatividade e Processos de Criação. $25^{\circ}$ ed. Petrópolis: Vozes Ltda. 2010.

PIROLA-MERLO, A.; MANN, L. The relationship between individual creativity and team creativity: aggregating across people and time. Journal of Organizational Behavior, 25, 2004, pp.325-257.

SNYDERMAN, M.; ROTHMAN, S. Survey of expert opinion on intelligence and aptitude testing. American Psychologist, v.42, 1987, 137-144. 
STERNBERG, R. J. Beyond IQ: a triarqui theory of human intelligence. Cambridge: Cambridge University Press, 1985.

STERNBERG, R. J. The Nature of Creativity. Creativity Research Journal, 2006, Vol. 18, No. 1, 87-98.

TAGGAR, S. Individual creativity and group ability to utilize individual creative resources: a multilevel model. Academy of Management Journal, 45(2), 2002, 315330.

TSCHIMMEL, K. C. Sapiens e Demens no pensamento criativo do design. Tese (Doutorado em Design). Universidade de Aveiro, Departamento de Comunicação e Arte, 2010.

WOODMAN, R. W., SAWYER, J. E., \& GRIFFIN, R. W. Toward an organizational theory of creativity. Academy of Management Review, 18, 1993, pp.293-321. 